\title{
EUDISED
}

THESAURUS MULTILINGÜE 



\section{CONSEJO DE EUROPA}

CENTRO DE DOCUMENTACÓN PARA LA EDUCACIÓN EN EUROPA

\section{EUDISED}

\section{THESAURUS MULTILINGÜE}

para el tratamiento de la información relativa a la educación

Primera edición española

\section{5}

Preparada por

JEAN VIET

Maison des Sciences de l'Homme, Paris 
ISBN: 9027976627

(C) 1976, Council of Europe and Mouton \& Co

\section{Printed in the Netherlands}

